\title{
LINGUAGENS AUDIOVISUAIS E CIDADANIA
}

\section{Abandonar preconceitos e procurar compreender as formas de expressão audiovisual é um exercício de cidadania necessário na escola}

A principal fonte de informação na sociedade contemporânea é a televisão. É, portanto, através da linguagem audiovisual que vem se formando a visão de mundo das novas gerações. Mais do que isso ainda, o hábito de receber comunicação através da TV está reorganizando a forma de expressão das crianças e dos jovens. Frases curtas, elipses, não linearidade na expressão do pensamento são algumas articulações expressivas que as novas gerações vêm exercitando, produzindo perplexidade e incompreensão por parte de pais e professores.

É preciso entender que as novas gerações refletem os modelos culturais do seu tempo nas formas de expressão que adotam. Do mesmo modo, a distância que se estabelece no diálogo entre as gerações é também determinada pela carga cultural traduzida pelos adultos.

A escola e os professores vêm procurando reduzir essas dificuldades trazendo para as salas de aula a discussão de vídeos, filmes e programas de TV. Apesar dos
A AUTORA
Marília Franco
Professora Doutora do Departamento de Cinema,
Rádio e Televisão da Escola de Comunicações e
Artes da USP. E-mail: mdsfranc@usp.br

grandes progressos já conseguidos, há ainda algumas inquietações que merecem uma reflexão.

É impossível pensarmos em formar um cidadão sem cuidar de construir uma visão histórica pela qual ele possa avaliar a herança cultural que lhe molda o pensamento e a ação.

No caso das relações da educação com as linguagens audiovisuais no Brasil, essa visão encontra-se desarticulada pela falta de informação histórica. A grande maioria dos professores desconhece, por exemplo, que a história do cinema educativo começa, entre nós, na década de $20^{1}$.

No momento de encarar o trabalho com vídeo na sala de aula, no entanto, esse professor torna-se vítima de uma série de medos e preconceitos historicamente sedimentados na prática pedagógica.

Assim, veja se estas frases não lhe são familiares:

- professor que passa filminho gosta de matar aulas!

- filminho deixa os alunos muito indisciplinados!

- eu não entendo nada de cinema, não me arrisco a passar filminho!

- os filmes educativos são muito chatos!

Esse espírito negativo foi laboriosamente construído a partir de inúmeros pro-

I. Sobre o assunto: MORETTIN, Eduardo. Cinema educativo: uma abordagem histórica. Comunicação $\&$ Educação. São Paulo: CCA-ECA-USP/Moderna, n.4, set./dez. 1995, p.13-19. 
jetos mal realizados de utilização das linguagens audiovisuais na educação. Quem quiser desenvolver, hoje, uma atividade produtiva e bem-sucedida com vídeos em sala de aula, precisa buscar resposta a essa determinação histórica não só entre os colegas resistentes, mas também no fundo de si mesmo, pois com certeza ainda restam algumas dessas dúvidas no coração de cada professor.

É preciso reconhecer que as dificuldades são genuínas e historicamente construídas, não cabendo espaço para sentimentos individuais de incapacidade ou culpa.

Para o professor poder formar sua cidadania audiovisual docente é preciso discutir os medos e preconceitos, reconhecer suas competências enquanto espectador/telespectador e pôr em foco essa pessoa social que gosta de TV e de cinema e o profissional-professor que pode levar essa competência para a sala de aula como apoio à atividade didática.

Somente reconhecendo os vícios de origem e respondendo com sinceridade àquelas frases acima relembradas, será possível reverter o peso das experiências frustradas.

\section{CIDADANIA E PRÁTICA PEDAGÓGICA}

Linhas de pensamento diferentes podem ser identificadas na abordagem das relações das linguagens audiovisuais com a educação no Brasil.

A Tecnologia Educacional, desenvolvida principalmente durante a década de 70 , nomeia hoje como recursos audiovisuais: cinema, vídeo, TV, slides sonorizados, multimídia. Nas suas abordagens mais superficiais trata-os como apoios pedagógicos ao professor, sem desenvolver, de forma mais detalhada, as possíveis mudanças qualitativas que tais recursos podem trazer à prática da construção do conhecimento.

Vem ainda da década de 70 uma tendência, que resultou num temor compreensível entre professores, de que a tecnologia pudesse reduzir ou mesmo substituir o docente como transmissor principal do conhecimento aos alunos.

Herdeira mais direta de um pensamento educacional que, na década de 20 , orientou, no mundo todo, a criação das chamadas "Cinematografias Educativas", desenvolveu-se, na década de 80 , a chamada Leitura Crítica dos Meios.

Nos anos 20 as instituições educacionais, religiosas e familiares promoveram o que chamo de julgamento moral do cinema comercial, do cinema de lazer que se produzia e que seduzia definitivamente grandes massas da população, principalmente crianças e jovens. $\mathrm{O}$ julgamento resultou numa condenação, ao mesmo tempo em que consagrava o reconhecimento de que, realmente, o cinema era capaz de fazer a cabeça do público.

A produção de um cinema educativo passou, então, a ser desenvolvida em todo o mundo. Desde as versões mais genéricas como filmes de lazer produzidos especialmente para crianças e jovens dentro de padrões aceitáveis pelas instituições - até filmes didáticos realizados dentro de rígidas normas pedagógico-cinematográficas.

Não vou ser radical dizendo que tudo isso era muito chato, mas devo reconhecer que esse foi o terreno fértil onde cresceu o preconceito de que falei acima.

Ainda que sem a radicalização da postura antiga, a Leitura Crítica dos Meios não tem ido muito além dos limites de uma 
análise de conteúdo das emissões audiovisuais em geral, deixando sempre no ar a incômoda dúvida de se a TV, o cinema e o vídeo não são um mal necessário para o mundo contemporâneo.

Não podemos nos esquecer, no entanto, de que, enquanto a educação se debate nesses terrenos, os meios audiovisuais continuam sendo consumidos largamente pelas pessoas, proporcionando um derrame de informação que, mesmo sem tratamento pedagógico, transforma-se em formação.

Modos de ver o mundo, de sentir, de atuar são orientados pela mídia e aceitos como modelos. E a contemporaneidade se constrói não pelo passe de mágica da tecnologia, mas pela sedução da linguagem carregada pelas tecnologias diversas, às quais o público é indiferente. Tanto faz ver Rambo no cinema, na TV ou no vídeo. $\mathrm{O}$ bom é ver Rambo, de preferência várias vezes, nos três suportes.

\section{CIDADANIA: UM PRESENTE PARA O FUTURO}

O bom é ver, espectar. É definitivamente o prazer de ver/ouvir a grande mágica sedutora das linguagens audiovisuais. Por isso mesmo tão persuasiva e pedagógica. Não creio que tenha mais nenhuma eficácia tentar negar ou minimizar esse festival dionisíaco. Um século de cinema plasmou esse hábito psicossocial de buscar alegria no jogo de ver/ouvir. A TV invadiu com esse prazer os espaços pessoais da casa e o vídeo resgatou o rever, $o$ (re)sentir.

A escola precisa encontrar, na parceria com o prazer audiovisual, a forma de res- gatar a alegria do contato humano entre professores e alunos. É gostoso desvendar juntos o sentido dos vídeos. Os professores que já definiram essa metodologia sabem com que renovado interesse são saboreados alguns conteúdos antes apenas tolerados como inevitáveis.

Mas a verdadeira lição de cidadania que a exploração renovada do audiovisual pode trazer aos estudantes é a partir da compreensão dos aspectos mais relevantes dessa linguagem: o desenvolvimento da leitura das formas de expressão audiovisual.

$\mathrm{O}$ aspecto mais importante para iniciar esse processo de leitura é o entendimento de que cada peça audiovisual expressa "um ponto de vista" - o do autor. Esse ponto de vista deve confrontar-se com aquele do leitor/espectador. A compreensão mais profunda do sentido da comunicação se dará exatamente na mescla, no confronto entre essas opiniões. Os parâmetros de verdade e mentira dão lugar a uma visão mais ampla, orientada por matrizes culturais, históricas, científicas, populares.

Esse exercício se fará naturalmente, na medida em que a mesma peça audiovisual pode e deve ser usada por vários professores, que farão dela suas interpretações especializadas a partir de sua área de conhecimento e da sua bagagem cultural e pessoal.

Também a bagagem pessoal e cultural do aluno precisa ser explorada nos debates que se promovem a partir das motivações audiovisuais. O conhecimento já não é mais o do professor, repetido pelo aluno, mas sim torna-se algo a ser adquirido e manipulado no jogo do raciocínio, da criação de relações de saberes vários, no desenvolvimento da competência de interpretar as fontes de informação reconhecendo, antes dos conteúdos, as linguagens próprias de cada mídia. 
A cidadania é o exercício de adaptação entre os desejos e deveres do eu-pessoal e do eu-social. $\mathrm{Na}$ formação do cidadão para viver no mundo contraditório que o progresso vem construindo não cabem mais ditaduras de pontos de vista. Lidar com as pluralidades é o grande desafio que se apresenta ao homem do futuro.

Desenvolver a capacidade de leituras plurais das informações com que as mídias nos bombardeiam diariamente, torna-se um exercício virtual de cidadania para a vida futura. Aprender a respeitar e a conviver com as diferenças é um grande legado que pre-

Resumo: A linguagem audiovisual do cinema e da televisão tem formado a visão de mundo das novas geraçōes. Dai a necessidade de se abandonar os preconceitos e trabalhar com elas no espaço pedagógico da escola. Esse é um exercício de cidadania que se impōe, possibilitando que professores e estudantes desenvolvam a compreensâo das formas de expressão audiovisual e o respeito às diferenças.

Palavras-chave: audiovisual, cidadania, educação, cinema cisamos deixar para as crianças e jovens. Compreendendo, antes de mais nada, as diferenças, sobretudo de expressão, que já marcam a convivência entre gerações.

A turma de hoje não é incompetente para escrever. Seus modelos de comunicação são diferentes. Melhores, piores? Impossível definir sem reconhecer as diferenças. Quem sabe a leitura conjunta das linguagens audiovisuais, entre professores $\mathrm{e}$ alunos, não ajude a recuperar o respeito mútuo dessas gerações, construindo as bases para um crescimento comum sem o peso autoritário das "verdades".

Abstract: The audio-visual language of cinema and television has formed the new generations'view of the world. Hence it is important to abandon prejudices and to deal with it within the pedagogical space of school. This exercise of citizenship is absolutely necessary in order to enable teachers and students to develop a comprehension of the different forms of audio-visual expression.

Key-words: audio-visual, citizenship, education, cinema 